Asian J. Med. Biol. Res. 2020, 6 (4), 611-617; doi: 10.3329/ajmbr.v6i4.51225

\author{
Asian Journal of \\ Medical and Biological Research \\ ISSN 2411-4472 (Print) 2412-5571 (Online) \\ www.ebupress.com/journal/ajmbr
}

\title{
Review \\ Common sage (Salvia officinalis) antiviral role: potentiality of a Unani hand sanitizer in COVID-19 (corona virus) second wave control
}

\author{
M A Momith Azad ${ }^{1 *}$, Abdullah-Al-Mahmud², Md Shahidul Islam³ and Ahmed Iqbal Gouhar ${ }^{4}$ \\ ${ }^{1}$ BUMS (DU), PGD (Dhaka), PhD (RU), Head of PDD, Research \& Development Division, Natural Medicine, \\ The IBN SINA Pharma Ltd. Bangladesh \\ ${ }^{2}$ MSS in Clinical Social Work (DU), BUMS (DU), Institute of Social Welfare and Research (DU) \\ ${ }^{3}$ MBBS, PhD (Applied Cell Sciences) Research Fellow, Tehran University of Medical Sciences, Iran \\ ${ }^{4}$ M.Sc (RU), B.Sc (Hons), Chief Microbiologist, The IBN SINA Pharmaceutical Ind. Ltd. Dhaka, Bangladesh
}

*Corresponding author: M A Momith Azad, Head of PDD, Research \& Development Division, Natural Medicine, The IBN SINA Pharma Ltd. Bangladesh. Phone: +8801716762630; E-mail: momithazad@yahoo.com

Received: 07 December 2020/Accepted: 29 December 2020/ Published: 31 December 2020

\begin{abstract}
The world has been fighting against a pandemic for more than a year, caused by a highly infectious disease named COVID-19 rooted by the novel coronavirus 2019. It has already been spread out in most of the countries and a few of which are experiencing second wave. The Novel coronavirus-2019 (SARS CoV-2) incurred more than 1.6 million deaths and 76 million cases in the world population (till 20 December 2020). Although some vaccines are being launched, however, their effectivity and availability are still unknown. Maintaining personal hygiene and social distance are the best way of protection. Hand washing is the utmost recommendation for the maintenance of personal hygiene since hands can be contaminated by the droplets easily. Particularly, in pandemic situations, it is crucial to interrupt the transmission chain of the virus by the practice of proper hand sanitization. The hand sanitization solely depends on the use of effective hand disinfecting agents. Natural formula-based disinfectants can be preferable to chemicals because of higher efficacy and lower adverse effects. Unani medicine is the system based on natural formulations. 'Raihan' (common sage, Salvia officinalis) is frequently used in Unani medicine for its higher disinfectant role. Common sage extract with ethanol may provide superior efficacy against COVID-19. In this article, we presented information on common sage and its potentiality using with ethanol as a natural, skin-friendly hand sanitizer to prevent harmful action of chemical mixing synthetic sanitizer.
\end{abstract}

Keywords: COVID-19; pandemic; SARS-CoV-2; Unani medicine; common sage

\section{Introduction}

At the end of 2019, outbreak of a coronavirus that caused respiratory-related illness was reported in Wuhan, Hubei, China, a disease now officially called "the Coronavirus Disease 2019; COVID-19" (Wu et al., 2020). This introduces the earth a worse and strange experience namely 'lockdown' which is new in this 21 st century. Health policy-makers and scientists are in great difficulties to provide a valid and effective guideline to control it. Till now maintaining social distance and personal hygiene is the best way to protect it. Vaccination started but potentiality is not yet disclosed. Hand washing is the first priority to maintain personal hygiene and protection against COVID-19. Washing hands often with soap and water for at least 20 seconds especially after have been in a public place, or after blowing nose, coughing, or sneezing. If soap and water are not readily available, using a hand sanitizer may be preferable which contains at least $60 \%$ alcohol. All surfaces of hands should be covered as well as rubbed them together until they feel dry. Touching eyes, nose, and mouth with unwashed hands should be avoided too (CDC, 2020). Different types of sanitizers are used as disinfectant 
purpose. Some may not be suitable and safe. From ancient era people use different natural sources and plants to clean their body and hands. Nowadays some ingredients are scientifically proved as a good and defensive for cleanliness having antimicrobial activities (Gyawali and Salam, 2014). Unani Tibb or Unani medicine is famous in curing and caring historically which consists of natural ingredients. It is a form of traditional medicine practiced in South-East and South-Asian countries. It is a comprehensive medical system, which meticulously deals with the various states of health and diseases. It provides promotive, preventive, curative and rehabilitative healthcare. The fundamentals, diagnosis and treatment modalities of the system are based on scientific principles and holistic concept of health and healing (NHP India, 2016). "Vui Tulsi" or Common sage is very common plant using in Unani medicine for internal and external protection from infective agents. Its Unani name is 'Raihan' (BNUF, 2011). Raihan or Vui Tulsi or Common sage (Salvia officinalis) is very important and effective anti-microbial agent containing plant. It has been reported that sage exerts a range of therapeutic activities including antibacterial, antiviral, antifungal, and antioxidant effects (Samuels et al., 2012).

\section{Structure of SARS-CoV-2}

Coronaviruses are enveloped virus. They have a single-stranded RNA genome and a neucleocapsid of helical symmetry. International Committee on Taxonomy of Viruses classified it into the subfamily Orthocoronaviridae, in the family Coronaviridae order Nidovirales, and realm Riboviria (ICTV, 2020).

Recent work shows that, like the virus that caused the 2002 SARS outbreak, SARS-CoV-2 spikes bind to receptors on the human cell surface called angiotensin-converting enzyme 2 (ACE2) (NIH, 2020). Coronaviruses are large pleomorphic spherical particles with bulbous surface projections (Goldsmith et al., 2004).
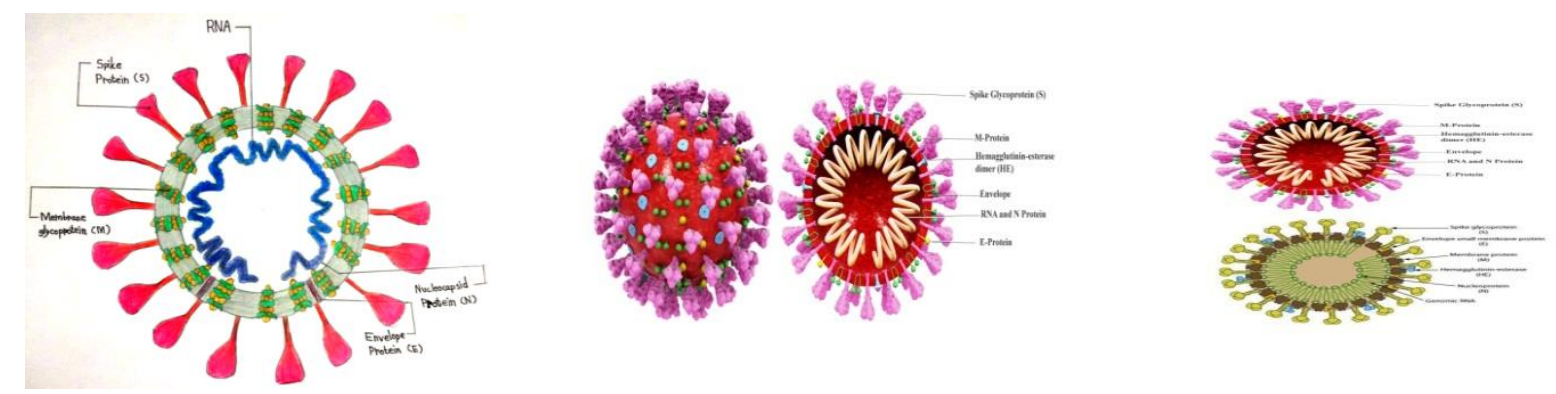

Figure 1. Schematic diagram of the SARS coronavirus structure (adopted with Peiris et al., 2004).

The viral envelope consists of a lipid bilayer where the membrane (M), envelope (E) and spike (S) structural proteins are anchored (Lai and Cavanagh, 1997). Inside the envelope, there is the nucleo-capsid, which is formed from multiple copies of the nucleocapsid $(\mathrm{N})$ protein, which are bound to the positive-sense singlestranded RNA genome in a continuous beads-on-a-string type conformation (Chang et al., 2014; Fehr et al., 2015). The lipid bilayer envelope, membrane proteins, and nucleocapsid protect the virus when it is outside the host cell (Neuman, 2011). SARS-CoV and other beta-coronaviruses recognize different receptors: MERS-CoV and HKU4 recognize a serine peptidase, dipeptidyl peptidase 4 (DPP4) (Raj et al., 2013; Yang et al., 2014). MHV recognizes a cell adhesion molecule, carcinoembryonic antigen-related cell adhesion molecule 1 (CEACAM1) (Dveksler et al., 1991; Williams et al., 1991).

\section{Sensitivity of the virus}

The virus is a self-assembled nanoparticle. The lipid (fatty) bilayer is the weakest link of it. This lipid membrane dissolved by soaps and it dies or falls apart or inactivated like a house of cards. Most viruses consist of three key building blocks: ribonucleic acid (RNA), proteins and lipids. Washing the virus off with water alone might work. But water is not good at competing with the strong, glue-like interactions between the skin and the virus. Water isn't enough to deactivate the virus. Firstly the soaps make the glue like bonds weaker what is present between the skin and the virus. Then, it follows the Velcro-like interactions holding the lipid, protein and RNA of the virus, which leads this to death or inactivation. The alcohol based solutions or disinfectant product where it is high in ration (60-80\%) kill viruses in same mechanism (Thordarson, 2020).

SARS-CoV-2 belongs to the beta CoVs category. It has round or elliptic and often pleomorphic form, and a diameter of approximately 60-140 nm. Like other CoVs, it is sensitive to ultraviolet rays and heat. Furthermore, 
these viruses can be effectively inactivated by lipid solvents including ether (75\%), ethanol, chlorine-containing disinfectant, peroxyacetic acid and chloroform except for chlorhexidine (Cascella et al., 2020).

\title{
4. Actions of ethanol against viruses (Unani name: Kuhool)
}

It has long been known that alcohols alter lipid bilayer properties and membrane protein function Methanol through nonanol increase the quenching rate. Alcohols have their-OH group in the bilayer interfacial region and their hydrophobic methyl groups in the hydrophobic core of the bilayer. The chain packing of the lipid acyl distracted. Every methyl group compensates the partition of alcohol coefficient additionally into the bilayer, but the bilayer-perturbing effect per molecule remains similar (Ingólfsson and Andersen, 2011).

Ethanol is an important and worldwide recognized for use in healthcare compound for hand rubbing. Report has been showed that, it has a broader and stronger activity as a virucidal agent. Ethanol, where its concentration is ranging from 70-90\%; effective against Murine norovirus and adenovirus type 5. There it may be compared with propanols. Ethanol inactivated these viruses in 30 seconds. Ethanol $80 \%$ is proved as an efficient compound against such types of viruses namely calicivirus (FCV), poliovirus, polyomavirus, foot-and-mouth disease virus (FMDV) and hepatitis A virus (HAV).Some studies show that ethanol at $95 \%$ is as a resistance breaker for poliovirus type 1 . This $95 \%$ concentration of ethanol is sought to be enough as an active for majority of the viruses whose are clinically relevant. Some additional acids can increase the virucidal activity of ethanol. If ethanol is in lower concentrations, we can use these additional substances as well as changing the flavor, color etc of it. FCV, pliovirus, polyomavirus, HAV, FMDV and some selected viruses may remain too resistant still. Also in that cases this associative agents can be added with ethanol. (Kamf, 2018).

\section{Unani Medicine}

Unaani is the other name of Greek and Unani medicine is an ancient system of medicine what was famous on there. Bases of Unani medicine lies on qualities of four temperaments and four humors. This medicine recognizes the mental, emotional, spiritual, and physical causes of illness or health. It believes that each individual should take responsibility for their own well-being. Claudius Galenus of Pergamum traced back to the threads that comprise Unani healing, who lived in the second century of the Common Era. Ibn Sina (Avicenna) collected the basic knowledge of Unani medicine as a healing system in 980 ce in the areas of Persia. Subsequently, Ajmal Khan, who was born in 1864 in India, is generally acknowledged to be the most significant twentieth century contributor to Unani medicine in this subcontinent (Lloyd, 2009).

Unani medicine encompasses a wide range of practices. Unani pharmacotherapy uses naturally occurring medicines what comes from three sources called 'Mawaleed e Salasa'. Mostly herbal medicines and those of animal and mineral sources also followed. Single medicines or combination in raw form of them are preferred over to compound formulations. Homeostasis of the body can be reserved by Unani physiotherapies what are the combination uses of specific exercise techniques to help balance the (WHO, 2010).

\section{Formulation}

An antiviral hand sanitizer formulation in the BNUF (Bangladesh National Unani Formulary) books effectiveness in viral sanitizer based on sage (Salvia officinalis) or common sage (BNUF, 2011).

\author{
7. Botanical classification Common sage (Unani name: Raihan) \\ Kingdom: Plantae \\ Division: Magnoliophyta \\ Sub-division: Angiosperms \\ Class: $\quad$ Magnoliopsida \\ Order: $\quad$ Lamiales \\ Family: Lamiaceae \\ Genus: $\quad$ Salvia \\ Species: $\quad$ S. officinalis \\ Botanical classification of common sage (Bown, 2001)
}




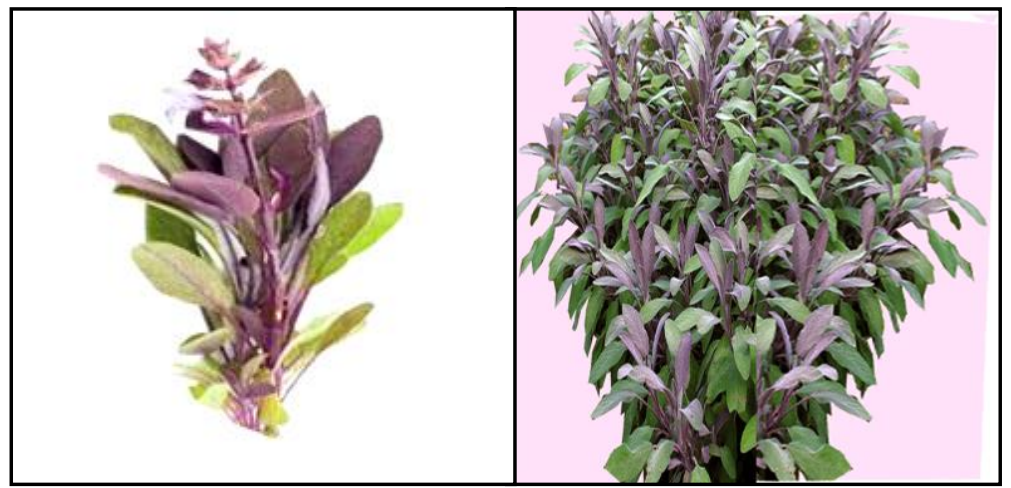

Figure 2. Common sage (Salvia officinalis) (Self captured).

\section{Antimicrobial activities of common sage 8.1. Antibacterial functions}

A study of the antibacterial activities of the essential oil of $S$. officinalis proved that sage essential oil in higher concentration exhibited a better efficiency than antibiotics. This has made sage essential oil a good alternative to the traditional antibiotics as well as food preservatives (Rami and Li, 2011).

A study conducted on the antibacterial effect of sage against selected food spoiling bacteria in vitro indicates that the sage aqueous extract exerted significant antibacterial activity and it was most effective against Bacillus mycoides, Bacillus subtilis, Enterobacter cloacae and Proteus sp. A study showed that sage, along with different plant extracts was comparable to synthetic preservatives, and the result confirmed that the aqueous extract of $S$. officinalis can be used in biotechnology as a natural preservative ingredient in food industry too (Stanojevic et al., 2010).

The findings of a study support the view that the hydroalcoholic extract of S. officinalis has growth inhibitory effect on some dental caries causing bacteria such as Streptococcus mutans, Lactobacillus rhamnosus, and Actinomyces viscosus. Based on this study and the global interest in using traditional treatments instead of chemical solutions, $S$. officinalis with its bactericidal effect could be a natural remedy for the treatment of diseases affecting mouth and teeth (Kermanshah et al., 2009). The SoEO (Salvia officinalis essential oil) showed an interesting activity against the Gram-positive pathogens ( $S$. aureus and M. luteus) and also a very good activity against $B$. cereus and $B$. subtilis with MIC values of 0.625 and $0.312 \mathrm{mg} / \mathrm{mL}$, respectively. (Delamare et al., 2007)

\subsection{Antiviral functions}

Salvia officinalis (Sage) is a plant in the family of Labiatae/Lamiaceae. These findings include anticancer, antiinflammatory, antinociceptive, antioxidant, antimicrobial, antimutagenic, antidementia, hypoglycemic, and hypolipidemic effects. In the aerial parts of $S$. officinalis is most susceptible for the antiviral activity which may mediated by safficinolide and sage one, two diterpenoids which are found on there (Tada et al., 1994).

From lamiaceae family, aqueous extracts can rapidly and drastically reduce the infectivity of non-cytotoxic concentrations of HIV-1 virions. Mode of action of the virion's density appears to be the most likely an extractinduced enhancement prior to its surface engagement. A strong activity against herpes simplex virus type 2 may also harbouring where these extracts more likely to provide a basis for the development of novel virucidal topical microbicides (Geuenich et al., 2008).

For a long time, medicinal plants have been used for the treatment of many infectious diseases, in most cases without a scientific background supporting their employment. On the contrary, at present, there is increasing emphasis on determining the scientific evidence and rationale use of preparations from medicinal plants. Thus, in the last several years, a large number of antiherpes screening experiments on medicinal plant extracts and plant-derived secondary metabolites (e.g., polyphenolics, glycosides, terpenes, polysaccharides, polyketides, pheophorbides, etc.) have been reported (Khan et al., 2005).

Many species of the Lamiaceae family are known for their antiviral activity. Among them, aqueous and ethanolic extracts of Salvia officinalis and Salvia coccinia revealed an important antiviral activity against HSV1 and HSV-2 (Rajbhandari et al., 2001; Schnitzler et al., 2008). 


\subsection{Anti-fungal functions}

Salvia officinalis L. essential oil is proved to have antifungal activities against dermatophyte strains (Darwish $e t$ al., 2013). In vitro testing of Fusarium mycotoxins, Salvia officinalis L. showed to having potentiality (Maria et al., 2013). It has essential oil proved the same antifungal effect for Botritis cinerea and Fusarium sp. (Daferera et al., 2003) and EO also has a high anti-fungal capacity against pathogen fungi like Verticillium dahliae and Penicillium aurantiogriseum (Rus et al., 2015)

\subsection{Insecticidal functions}

Good to moderate inhibitions were recorded for most of tested microorganisms. Salvia officinalis also exhibited important insecticidal activity against Spodoptera littoralis larvae and Tribolium castaneum adults with $\mathrm{LC}_{50}$ values of 55.99 and $97.43 \mu \mathrm{l} / \mathrm{L}$ airs, respectively. The effect of the SoEO on seeds germination and growth showed different activities against radical and hypocotyl elongation of the tested species (Khedher et al., 2017)

\subsection{Rationale of ethanol in combination with extract of Salvia officinalis}

Viruses consist of nucleic acids, proteins and lipids. When glue like interaction exists between skin and virus, water is unable to remove it. Soaps, alcohols or other disinfectants are highly in needs. - $\mathrm{OH}$ and these groups are proved as perturbing agent of that lipid chain of the virus. Ethanol has a stronger and broader virucidal activity. Ethanol $80 \%$ is unlikely to be sufficiently effective against poliovirus, calcivirus, polyomavirus, hepatitis A virus and foot-and-mouth disease virus. The spectrum of virucidal activity of ethanol at $95 \%$, however, covers the majority of clinically relevant viruses (Kamf, 2018).

Studies showed that sage, along with different plant extracts was comparable to synthetic preservatives, and the result confirmed that the aqueous extract of $S$. officinalis can be used in biotechnology as a natural protective ingredient (Stanojevic et al., 2010). Hydroalcoholic extract of S. officinalis has growth inhibitory effect on different bacterias like Streptococcus mutans, Lactobacillus rhamnosus, and Actinomyces viscosus found in different scientific experimental studies. In addition, common sage has been found active against the Grampositive pathogens (S. aureus and M. luteus) and also a very good activity against $B$. cereus and $B$. subtilis with MIC values (Delamare et al., 2007).

Thereby, the synergistic effect of both ethanol and sage extract could be effective against harmful microorganisms and ideal alternative for them who have sensitivity to chemical sanitizers available in the market.

\section{Conclusions}

The novel coronavirus 2019 has emerged a global crisis for human health. Vaccination started but not covered and showed enough potentiality. As the saying goes "Prevention is better than cure". In that sense, the World Health Organization (WHO) emphasized on hand washing along with other protective measures. In this review, we focus on the Sage cleanser, made with ethanol and Salvia officinalis (according to Bangladesh National Unani Formulary). The proposed formulation for topical use might be potent in killing wide range of harmful micro-organisms especially SARS-CoV-2 to ensure primary protection against COVID-19. There is scope for sophisticated research to explore exact molecular mechanism in killing microorganisms, toxicity to human health and also to estimate precise concentration of extract and ethanol. Due to having some specific anti-viral and antimicrobial activity in the common sage (Salvia officinalis) the possibility of the proposed (Unani hand sanitizer) will be very potential for COVID-19 (coronavirus) second wave control.

\section{Conflict of interest}

None to declare.

\section{References}

Bangladesh National Unani Formulary (BNUF), 2011. Register, Bangladesh Unani and Ayurvedic Board, Dhaka, Bangladesh, pp. 819-821.

Bown D, 2001. The Herb Society of America New Encyclopedia of Herbs and Their Uses. New York: DK.

Cascella M, M Rajnik, A Cuomo, SC Dulebohn and RD Napoli, 2020. Features, Evaluation and Treatment Coronavirus (COVID-19). StatPearls, April 6, 2020.

Centers for Diseases Control and Preventions (CDC), 2020. Coronavirus Disease 2019 (COVID-19), How to Protect Yourself \& Others. Available: https://www.cdc.gov/coronavirus/2019-ncov/prevent-gettingsick/prevention.html.

Chang CK, MH Hou, CF Chang, CD Hsiao and TH Huang, 2014. The SARS coronavirus nucleocapsid protein forms and functions. Antiviral Res., 103: 39-50. 
Darwish MSA, C Cabral, IV Ferreira, MJ Goncalves, C Cavaleiro, MT Cruz, TH Al-Bdour and L Salgueiro, 2013. Essential Oil of common sage (Salvia officinalis l.) from Jordan: Assessment of safety in mammalian cells and its antifungal and anti-inflammatory potential. BioMed. Res. Int., 2013: 1-9.

Daferera D, B Ziogas and M Polissiou, 2003. The effectiveness of plant essential oils on the growth of Botrytis cinerea, Fusarium sp. and Clavibacter michiganensis subsp. Michiganensis, Crop Prot., 22: 39-44.

Delamare LAPL, TMP Ivete, L Artico, LA-Serafini and S Echeverrrigary, 2007. Antibacterial activity of the essential oils of Salvia officinalis L. and Salvia triloba L. cultivated in South Brazil. Food Chem., 100: 603608.

Dveksler GS, MN Pensiero, CB Cardellichio, RK Williams, GS Jiang, KV Holmes and CW Dieffenbach, 1991. Cloning of the mouse hepatitis-virus (MHV) receptor: expression in human and hamster cell lines confers susceptibility to MHV. J. Virol., 65: 6881-6891.

Fehr AR and S Perlman, 2015. Coronaviruses: an overview of their replication and pathogenesis, Methods in Molecular Biology. Methods Mol. Biol., 1282: 1-23.

Geuenich S, C Goffinet, S Venzke, S Nolkemper, I Baumann, P Plinkert, J Reichling and Oliver TK, 2008. Aqueous extracts from peppermint, sage and lemon balm leaves display potent anti-HIV-1 activity by increasing the virion density. Retrovirology, 5: 27.

Goldsmith CS, KM Tatti, TG Ksiazek, PE Rollin, JA Comer, WW Lee, PA Rota, B Bankamp, WJ Bellini and SR Zaki, 2004. Ultrastructural characterization of SARS coronavirus. Emerg. Infect. Dis., 10: 320-326.

Gyawali R and SA Ibrahim, 2014. Natural products as antimicrobial agents, Food Control. 46: 412-429.

ICTV, 2020. Naming the 2019 Coronavirus. Available at: https://talk.ictvonline.org/.

Ingólfsson HI and OS Andersen, 2011. Alcohol's Effects on Lipid Bilayer Properties. Biophys. J., 101: 847855.

Kamf G, 2018. Efficacy of Ethanol against Viruses in Hand Disinfection. J. Hosp. Infect., 4: 331-338.

Kermanshah H, SH Kamangar, S Arami, A Mirsalehian, M Kamalineghad, M Karimi and FJ Amoli, 2009. In vitro evaluation of antibacterial activity of hydroalcoholic extract of Salvia officinalis and Pimpinella anisum against cariogenic bacteria. J. Dent. Med., 22:149-154.

Khan MTH, A Ather, KD Thompson and R Gambari, 2005. Extracts and molecules from medicinal plants against herpes simplex viruses. Antivir. Res., 67: 107-119.

Khedher MRB, SB Khedher, I Chaieb, S Tounsi and M Hammami, 2017. Chemical composition and biological activities of Salvia officinalis essential oil from Tunisia. EXCLI J., 16: 160-173.

Lai MM and D Cavanagh, 1997. The molecular biology of coronaviruses. Adv. Virus Res., 48: 1-100.

Lloyd I, 2009. Traditional and complementary systems of medicine. The Energetics of Health, 1st Edt., pp. 2325.

Maria SR, A Ersilia and PM Atena, 2013. Assessment of inhibitory potential of essential oils on natural mycoflora and Fusarium mycotoxins production in wheat. Chem. Cent. J., 7: 32.

Miah MAH, M Hasan, YA Sarker, MM Alam and NS Juyena, 2017. Clinical evaluation of ethanolic extract of curcumin (Curcuma longa) on wound healing in Black Bengal goats. J. Adv. Vet. Anim. Res., 4: 181-186.

National Health Portal of India (NHP India), 2016. Unani: The Science of Health and Healing, AYUSH. Available: https://www.nhp.gov.in/unani_mty.

Neuman BW, G Kiss, AH Kunding, D Bhella, MF Baksh, S Connelly, B Droese, JP Klaus, S Makino, SG Sawicki, SG Siddell, DG Stamou, IA Wilson, P Kuhn and MJ Buchmeier, 2011. A structural analysis of M protein in coronavirus assembly and morphology. J. Struct. Biol., 174: 11-22.

Peiris JSM, Y Guan and KY Yuen, 2004. Severe acute respiratory syndrome. Nature Medicine, 10: S88-S97.

Raj VS, HH Mou, SL Smits, DHW Dekkers, MA Muller, R Dijkman, D Muth, JAA Demmers, A Zaki, RAM Fouchier, V Thiel, C Drosten, PJM Rottier, ADME Osterhaus, BJ Bosch and BL Haagmans, 2013. Dipeptidyl peptidase 4 is a functional receptor for the emerging human coronavirusEMC. Nature, 495: 251-254.

Rajbhandari M, U Wegner, M Julich, T Schopke and R Mentel, 2001. Screening of Nepalese medicinal plants for antiviral activity. J. Ethnopharmacol., 74: 251-255.

Rami K and Z Li, 2011. Antimicrobial activity of essential oil of Salvia officinalis L. collected in Syria. Afr. J. Biotech., 10: 8397-8402.

Rus CF, P Georgeta, E Alexa, Renata MS and Dana MC, 2015. Antifungal activity and chemical composition of Salvia officinalis L. essential oil. Res. J. Agric. Sci., 47(2).

Samuels N, JT Grbic, AJ Saffer, ID Wexler and RC Williams, 2012. Effect of an herbal mouth rinse in preventing periodontal inflammation in an experimental gingivitis model: a pilot study. Compend. Contin. Educ. Dent., 33: 204-206, 208-211. 
Schnitzler P, S Nolkemper, FC Stintzing and J Reichling, 2008. Comparative in vitro study on the anti-herpetic effect of phytochemically characterized aqueous and ethanolic extracts of Salvia officinalis grown at two different locations. Phytomedicine, 15: 62-70.

Stanojevic D, L Comic, O Stefanovic and SS-Sukdolak, 2010. In vitro synergistic antibacterial activity of Salvia officinalis and some preservatives. Arch. Biol. Sci., 62: 175-83.

Tada M, K Okuno, K Chiba, E Ohnishi and T Yoshii, 1994. Antiviral diterpens from Saliva officinialis. Phytochemistry, 35: 539-541.

Thordarson P, 2020. The science of soap - here's how it kills the coronavirus. The Guardian, Thu 12 Mar 2020, 09.40 GMT. Last modified on Wed 18 Mar 2020. Available: https://www.theguardian.com/commentisfree/2020/mar/12/science-soap-kills-coronavirus-alcohol-baseddisinfectants.

Williams RK, GS Jiang and KV Holmes, 1991. Receptor for mouse hepatitis virus is a member of the carcinoembryonic antigen family of glycoproteins. Proc. Natl. Acad. Sci. USA., 88: 5533-5536.

World Health Organization (WHO), 2010. Benchmarks for training in Unani medicine. Geneva, Page: 1.

Wu F, S Zhao, B Yu, YM Chen, W Wang, ZG Song, Y Hu, ZW Tao, JH Tian, YY Pei, ML Yuan, YL Zhang, FH Dai, Y Liu, QM Wang, JJ Zheng, L Xu, EC Holmes and YZ Zhang, 2020. A new coronavirus associated with human respiratory disease in China. Nature, 579: 265-269.

Yang Y, L Du, C Liu, L Wang, C Ma, J Tang, RS Baric, S Jiang and F Li, 2014. Receptor usage and cell entry of bat coronavirus HKU4 provide insight into bat-to-human transmission of MERS coronavirus. Proc. Natl. Acad. Sci. USA., 111: 12516-12521. 